\title{
Pulmonary hydatidosis patterns and clinical outcomes
}

\section{Shadi Hamouri ${ }^{1}$, Abdel Rahman Al manasra ${ }^{1}$, Hamzah Daradkeh ${ }^{1}$, Hanan Hammouri ${ }^{2}$, Nabil Al-} Zoubi $^{1}$, and Nathan Michael Novotny ${ }^{1}$

1. Department of General Surgery and Urology, Faculty of Medicine, Jordan University of Science and

Technology, Jordan

2. Faculty of Science and Arts, Jordan University of Science and Technology, Jordan

\section{RESEARCH}

Please cite this paper as: Hamouri S, Al manasra A, Dradkeh $\mathrm{H}$, Hammouri $\mathrm{H}$, Al zoubi N, Novotny NM. Pulmonary hydatidosis patterns and clinical outcomes. AMJ 2018;11(2):135-142.

https://doi.org/10.21767/AMJ.2018.3345

\section{Corresponding Author:}

Shadi Hamouri

Department of General Surgery and Urology

Faculty of Medicine

Jordan University of Science and Technology

P. O. Box 3030, 21110 Irbid, Jordan

Email: smhamouri@just.edu.jo

\section{ABSTRACT}

\section{Background}

Pulmonary hydatidosis remains a significant health problem in endemic areas. The clinical patterns and presentation vary according to the size, number, location and integrity of the cyst.

\section{Aims}

The aim of this study is to retrospectively evaluate the pattern and outcomes of patients diagnosed with pulmonary hydatidosis treated surgically in a tertiary hospital in northern Jordan.

\section{Methods}

A retrospective review of patients with pulmonary hydatidosis between December 2009 and December 2017 were performed. Data regarding demographic features, clinical presentation, serology testing, clinical outcomes and duration of medical treatment after surgery were obtained. Chest X-Ray and computerized tomography as well as liver ultrasound were the main methods of diagnosis. Parenchyma preserving excisions of the laminated membrane with capitonnage of the remaining cavity were performed in all patients. Albendazole was prescribed for 36 months postoperatively.

\section{Results}

Eighty-eight patients were involved. Mean age was $29.5 \pm 16.7$ years (range $8-75$ ). Females comprised 52 per cent of the patients. The main presenting symptoms were cough, dyspnea and chest pain. Thirty-two (37 per cent) patients had rupture of the cyst at the time of the presentation; 15 patients had direct rupture, 10 had communicating rupture and contained rupture was diagnosed in seven patients. Multiple and/or bilateral lesions were encountered in 25/88 (28.5 per cent) and 15 (17 per cent) patients respectively. Lower lobes were involved in 73.8 per cent of the cases. The mean hospital stay was $6.53 \pm 2.83$ days. Post-operative morbidities were developed in 12/88 (13 per cent) patients with air leak (5 per cent) as the most common morbidity. No recurrences or mortalities were reported in the follow up period.

\section{Conclusion}

Parenchyma preserving cyst excision with capitonnage provides a low postoperative morbidity in patients with both intact and complicated pulmonary hydatidosis. To decrease the risk of recurrence albendazole treatment is indicated postoperatively especially for recurrent, complicated and multiple hydatid cysts.

\section{Key Words}

Pulmonary hydatid cyst, rupture, capitonnage, albendazole

\section{What this study adds:}

\section{What is known about this subject?}

Pulmonary hydatidosis is a significant health problem. Its management is primarily surgical excision of the cyst. The management of the remaining cavity is controversial. 


\section{What new information is offered in this study?}

Excision of the cyst with obliteration of the remaining cavity followed by albendazole treatment is associated with very low post-operative complications and recurrence.

3. What are the implications for research, policy, or practice?

There is a need to conduct a randomized controlled multicentre prospective study to standardize the best surgical method of treatment and duration of medical treatment.

\section{Background}

Echinococcosis (Hydatid disease) is an infection caused by the tapeworm Echinococcus. E. granulosus and $E$. multilocularis are the most common species to cause infection in humans. The disease involves dogs as a definitive host, and sheep as an intermediate host. Man is considered an occasional intermediate host that can be infested by ingesting embryonated eggs. Once an embryo is released, with the aid of its hooklets, it attaches and penetrates the mucosa of the small intestine, and enters mesenteric venules, proceeding into portal circulation where it gets retained in the liver sinusoids. Some embryos bypass liver sinusoids through hepatic veins and inferior vena cava (IVC) into the right heart and finally lungs. ${ }^{1,2}$ Occasionally, embryos may travel through intestinal lymphatics into thoracic duct and then to the lungs through the right side of the heart. This explains the predominance of human hydatid disease in liver, followed by lungs as the second most commonly involved organs. ${ }^{1}$

The distribution of hydatid disease is variable between different parts of the world, it is considered a significant public health problem in South America and the Middle East, while the highest prevalence rates (8.7 per cent) have been reported among Mongolian and Kazak pastoralist communities. ${ }^{2}$ In Jordan, human cystic echinococcosis is one of the most important endemic infectious diseases. ${ }^{3}$

Clinical manifestations can vary from completely asymptomatic disease to a complex, extensive illness with systemic consequences. The potential severity of the disease pushes endemic countries to prevention by control measures and public education.

The aim of this study is to review our experience in diagnosis and management of pulmonary hydatid disease, with emphasis on surgical technique and clinical outcomes.

\section{Method}

This is a retrospective study conducted between December 2009 and December 2017. This study was approved by the ethics committee at our institution and patients' confidentiality was protected in accordance with declaration of Helsinki provisions. Patients included were managed at King Abdullah University Hospital. The hospital database was searched for lung hydatid disease during this period. Medical records of affected patients were reviewed. Data regarding demographic features, clinical presentation, serology testing, clinical outcomes (hospital stay, surgery complications and recurrence) and duration of medical prophylaxis after surgery were obtained. We also reviewed radiologic characteristics of the disease to record variance in cyst size, number, location and integrity at the time of diagnosis.

Prior to surgery, hematology and biochemical tests, including kidney (KFT) and liver function (LFT) assessment as well as complete blood count ( $\mathrm{CBC}$ ) including peripheral eosinophils count were routinely performed. IgG enzymelinked immunosorbent assay ELISA test was checked and a plain chest radiography (CXR) with Computerized tomographic scan (CT) was obtained for all patients, too. Ultrasound of the abdomen or inclusion of the upper abdomen in the performed CT of the chest is done in all patients to rule out liver involvement.

Although hydatid cyst can be suspected based on CXR (Figure 1), our standard radiological investigation to illustrate the findings was CT of the chest. Findings suggestive of lung hydatid disease included multiple or solitary rounded cystic lesions, predominantly found in lower lobes, with hypodense content relative to the capsule (Figure 2A). The identification of air-fluid level within cavity and collapsed laminated layers was consistent with direct intrabronchial or intrapleural rupture of hydatid cyst (Figure 2B). The 'water lily' sign of endocyst membrane floating on top of fluid -due to collapse of endocyst and partial drainage of fluid- was also seen in cases with suspected cyst rupture. Moreover, a cyst-bronchial communication was suggestive of endobronchial rupture, especially if associated with coughing up the laminated membrane.

The standard treatment for pulmonary hydatidosis was surgical excision. The procedure plan and selection relied on the size, rupture, multiplicity and bilaterality of the cysts as well as the presence of lung parenchyma destruction. When a patient had bilateral cysts, we performed a staged excision with 6-8 weeks, starting with the side that contains the large cyst or a non-complicated cyst. In patients with 
multi-organ involvement our strategy was to treat the lesions of the lungs first followed by the other sites in a separate surgical session. All efforts were made to preserve as much as we can of the lung parenchyma and to obliterate the residual cavity. All procedures were done under general anesthesia with double lumen intubation. After a muscle sparing anterolateral thoracotomy incision, the chest is entered, then the cyst is identified, the field is protected and packed with multiple impregnated pads with a scolicidal agent (hypertonic saline 10 per cent or povidone-iodine 10 per cent). Most of the intact cysts can be easily enucleated. The enucleation procedure involves opening of the pericystic membrane and then dissection gently around the laminated membrane to deliver the intact laminated membrane with assistance of positive pressure ventilation and surgeon's fingers (Figure 3 ). In cases of huge cysts, ruptured cysts, deep seated cysts in the lung parenchyma and tense cysts with pending rupture we open the pericystic membrane and then we aspirate all of the fluid contents of the laminated membrane, after that the laminated membrane will be removed making every effort to prevent spillage of the fluid. The residual space is dealt with after Allende and Lange technique ${ }^{1}$ that is closure of the major air leak sites separately and then capitonnage of the whole cavity using PDS $4 / 0$ or $3 / 0$ sutures (Figure $4 A$ and $4 B$ ). After testing for air leak sites and closing them, a chest tube is inserted and the chest cavity is closed. There was no anatomical resection for any patient in this series.

To decrease the risk of recurrence patients were usually started on albendazole (antiparasitic agent), 10$15 \mathrm{mg} / \mathrm{kg} /$ day divided in two doses with a maximum dose of $800 \mathrm{mg} /$ day, started either in the immediate postoperative period to avoid the incidence of cyst rupture if the patient has intact cyst ${ }^{4}$ or at the time of diagnosis if the patient has an already ruptured cyst. The treatment continued for three months after operation in patients with intact pulmonary cyst, and for six months in patients with ruptured, recurrent, multiple or multi-organ hydatid disease.

We followed our patients after surgery monthly for the first 6 months. During follow up, a clinical, biochemical (CBC and LFT) as well as radiological evaluation by (CXR) is performed. After that annual follow up visits were arranged.

\section{Statistical analysis}

Data were expressed as mean and range for continuous data. Statistical analysis was performed using JMP ${ }^{\circledR} 13$ software. $P$ value less than 0.05 was considered statistically significant.

\section{Results}

Over the eight-year study period, 593 patients underwent thoracotomy at our center, 88/593 had pulmonary hydatid disease, confirmed by gross inspection during surgery or by histopathology, or by both. All surgeries were performed by a single surgeon. Forty-six patients were females, with male: female ratio of 1:1.1. Mean age was 29.5 years (range $8-75$ years). Lung hydatid cysts were incidentally discovered in 24 per cent $(21 / 88)$ of subjects. Symptomatic patients presented mainly with cough (43 per cent), in which it was the only presenting symptom (22 per cent) or combined with other symptoms (21 per cent). Other presenting symptoms were shortness of breath (19 per cent) and, or chest pain (14 per cent). Table 1 summarizes clinical and demographic features of study patients.

Based on radiologic findings, 17 per cent of patients' lung lesions were bilateral. About one third (30 per cent) of patients had extra pulmonary involvement. The most commonly involved extra thoracic organ was liver (26 per cent), followed by spleen ( 3 per cent). CT scan was highly suggestive of ruptured lung cyst in 37 per cent of cases. Table 2 demonstrates the main cyst characteristics.

In our series, 32/88 (37 per cent) patients presented with ruptured cyst, of those, the most common was into the pleural cavity (15/32, 47 per cent). Those patients presented with pleural effusion, pneumothorax or hydropneumothorax with all consecutive symptoms and signs. The other type of rupture was into the endobronchial system which occurred in 10 patients who presented with cough of salty watery material, hemoptysis and even coughing up the whole laminated membrane in two patients, complete radiological disappearance of the cyst and the cavity was evident in one of them. The remaining patients got a contained rupture. All of these ruptures occurred spontaneously except one patient who had an iatrogenic rupture into the pleural cavity, this took place after a transthoracic CT guided biopsy of a thick wall lesion for suspected malignancy. This was the only patient in our study who developed anaphylaxis and was ultimately treated successfully.

Clinical outcomes, including duration of hospital stay, postoperative complications and disease recurrence on follow up are summarized in Table 3. Twelve patients (13 per cent) developed postoperative complications. The most common postoperative morbidity ( 5 per cent) was prolonged air leaks (more than seven days). Other rare complications like pneumothorax or surgical emphysema were noted after removal of the chest tube. Most of those patients had been 
treated conservatively either by keeping the chest tube for a longer period or re-insertion of a chest tube (only in three patients). Four (5 per cent) patients underwent re-operation (1 for empyema thoracis, 1 for postoperative bleeding, and 2 for prolonged air leaks).

One patient developed hemoptysis three months after surgery, likely secondary to infection at the site of surgery. A CT showed a persistent cavity at the site of surgery. Bleeding was controlled by angiographic embolization of the feeding vessel. Nine patients (10 per cent) of the study group were operated previously in other centers underwent re-operation due to recurrence. Most of them had a history of rupture prior to the first surgery. There was no recurrence and no mortality in this study during the follow up period.

Statistical analysis showed that there was no significant correlation between age, gender, size, and involved lobes with the post-operative complications and duration of the hospital stay. In addition, there was no statistically significant correlation between the cyst rupture and postoperative complication or hospital stay ( $p$ value 0.17 and 0.15 respectively).

\section{Discussion}

Cystic echinococcosis is a globally distributed illness with high prevalence in the countries of northern Africa, southern and eastern Europe, the southern tip of South America, and the eastern part of the Mediterranean region, including Jordan. ${ }^{5}$

Multiple studies from Jordan have estimated an overall mean annual surgical incidence (MASI) of about 2.3-2.9 per 100,000 inhabitants. ${ }^{6}$ With a higher incidence in the more rural eastern and south-western governorates. The highest calculated relative surgical index (RSI) was 3.4 among cases originated from the southern region. ${ }^{7}$ The lungs were the second most commonly involved organ (12 per cent of surgical cases), exceeded only by the liver. ${ }^{6}$

The exact prevalence of hydatid disease is our country is still unclear. Calculating the prevalence does not correspond with this study design, and requires further investigation.

The symptomatic pulmonary hydatid disease commonly presents with cough either due to cyst compression effect or direct endobronchial rupture, shortness of breath and or chest pain. However, less common presentations have been encountered in our population, including hemoptysis, and sinus discharge. The mechanism of hemoptysis may be due to pressure erosion of a bronchus or an obstructive effect with bronchial infection. ${ }^{8}$ One patient with a previous history of intra-pleural rupture of lung hydatid cyst came back a few years after with a sinus opening at the scar of chest tube insertion site. CT scan showed disease recurrence with multiple cysts, one of them penetrated the intercostal muscles to drain as a sinus on the chest wall.

Multiple reports demonstrated that the right lung is more commonly involved than left lung, especially the inferior lobe, ${ }^{9,10}$ which can be attributed to the rich blood circulation of this area. ${ }^{11}$ In our series, left lung was involved in 56 per cent $(41 / 73)$ of patients with unilateral lung disease. Cysts occupied the lower lung lobes in 73.8 per cent of them.

Although the open surgical technique is still the standard of care in the management of hydatid cyst, there are increasing numbers of surgeons who treat pulmonary hydatidosis with video-assisted thoracoscopic (VATS) technique. ${ }^{12}$ VATS can be used for ruptured cysts as well as intact cyst. Alpay and colleagues have suggested that VATS is best for non-recurrent single lesions that are peripherally located and not less than $2 \mathrm{~cm}$ or more than $10 \mathrm{~cm}$ in diameter. ${ }^{13}$ Cysts that are smaller than $2 \mathrm{~cm}$ are not considered for VATS due difficulty to locate it within the lung parenchyma especially if it is deeply seated. ${ }^{13}$ Moreover, all of these small lesions are considered for medical treatment before considering surgery. Strong evidence (randomized-controlled studies) to support the advantage of VATS for treatment of hydatid cyst over the standard conventional open technique is still lacking. In addition, many of our patients had either centrally located or multiple ipsilateral cysts, which contributed to our selection of open technique as a standard of care for pulmonary hydatidosis. The Puncture, Aspiration, Injection and Reaspiration (PAIR) procedure was avoided in the pulmonary hydatidosis since it carries a high risk of rupture and contamination. ${ }^{13}$

The obliteration of the post cyst resection cavity (capitonnage) is controversial. ${ }^{14}$ Some reports including most of large series advocated the use of cappitannage as part of the procedure to reduce the risk of prolonged air leak, development of empyema and residual space and therefore the hospital stay. ${ }^{15,16}$ This is also shown in our series as more than 70 per cent of the patients were discharged home before the $7^{\text {th }}$ postoperative day. In some reports capitonnage was not part of treatment. ${ }^{17}$ other surgeons argued against capitonnage as they believed it added no benefit and increased complications such as atelectasis. ${ }^{18}$ 
The commonest post-operative complication that was associated the extra days in-hospital was air leak. We believe that capitonnage may be of added value in reducing the risk of post-operative air leaks especially if it is performed in a non-infected or severely inflamed pericystic lung parenchyma. ${ }^{19}$

Rupture of the pulmonary hydatid cyst is considered the most common complication and it is strongly related to the size of the lesion and the increment in the intraluminal pressure of the cyst. In one study, it complicated 49 per cent of the cases. ${ }^{20}$ The rupture of the cyst can be divided into three clinical subtypes: ${ }^{21} 1$. Contained rupture in which the laminated membrane is ruptured while the pericyst is intact, 2. Communicating rupture that includes rupture of the laminated membrane and the pericyst is perforated by a bronchiole or bronchi. This type of rupture is associated with coughing up a salty watery material and associated with endobronchial spread of the disease. 3. Direct rupture that composed of opening of both the laminated membrane and the pericyst into the pleural cavity. The sequence of this rupture includes anaphylaxis, pleural spread of the disease and it may be associated with high recurrence rate of the disease.

Although some studies showed a higher postoperative morbidity and mortality in ruptured cysts, $^{22}$ Our study showed no correlation.

Our study is retrospective in nature and subject to all the limitations inherent to that method of analysis. In spite of these limitations, we analyzed patterns and clinical outcomes of pulmonary hydatid disease in our population with attention to the surgical technique and its outcome as well as the types of cyst ruptures. This study is, to date, the largest volume study investigating lung hydatid disease in Jordan.

\section{Conclusion}

Surgical treatment should be the primary option for pulmonary hydatidosis. Parenchyma preserving cyst excision with capitonnage provides a low postoperative morbidity in patients with both intact and complicated pulmonary hydatidosis mainly prolonged air leak and secondary infection. To decrease the risk of recurrence albendazole treatment is indicated postoperatively especially for recurrent, complicated, multiple and multiorgan hydatid cysts.

\section{References}

1. Dougusoy I. Management of Hydatid Cyst in: Kenneth L. Franco, Joe Putnam (eds.) Advanced Therapy in Thoracic Surgery, $2^{\text {nd }}$ edition, PMPH, USA; 2005.p.241-250.

2. Wang GZ, Feng $X H, C h u X D$, et al. Epidemiological study on human echinococcosis in Hobukesar Mongolian autonomous county of Xinjiang. Chin J Endemiol. 2009;28:214.

3. Kamhawi SK, Abdel-Hafez SA. Kamhawi Cystic echinococcosis in the Levant Countries (Jordan, Palestinian Autonomy, Israel, Syria and Lebanon) Adersen $\mathrm{H}$, Kachani M, Mouhelli FL (Eds.), Compendium on cystic echinococcosis in Africa and Middle Eastern Countries with Special Reference to Morocco, Brigham Young University, Provo UT; 1997, p. 292-316.

4. Usluer O, Kaya SO, Samancilar O, et al. The effect of preoperative albendazole treatment on the cuticular membranes of pulmonary hydatid cysts: should it be administered preoperatively? Kardiochir Torakochirurgia Pol. 2014;11(1):26-29. doi:10.5114/kitp.2014.41926.

5. WHO fact sheets, available on http://www.who.int/mediacentre/factsheets/fs377/en/, accessed on 28.01.2018

6. Kamhawi S, Hijjawi N, Abu-Gazaleh A, et al. Prevalence of hydatid cysts in livestock from five regions of Jordan. Ann Trop Med Parasitol. 1995;89(6):621-629.

7. Al-Qaoud KM, Craig PS, Abdel-Hafez SK. Retrospective surgical incidence and case distribution of cystic echinococcosis in Jordan between 1994 and 2000. Acta Trop. 2003;87(2):207-214.

8. Toleti S, Subbarao M, Dwarabu P. Hydatid disease of the lung presenting with hemoptysis and simulating a lung abscess. Trop Parasitol. 2012;2(1):69-70. doi:10.4103/2229-5070.97248

9. Bagheri R, Haghi S.Z., Amini M, et al. Pulmonary hydatid cyst: analysis of 1024 cases. Gen Thorac Cardiovasc Surg. 2011;59(2):105-109. https://doi.org/10.1007/s11748010-0690-z

10. Sarkar M, Pathania R, Jhobta A, et al. Cystic pulmonary hydatidosis. Lung India. 2016;33(2):179-191. doi:10.4103/0970-2113.177449.

11. Pirmoazen N, Saidi F, Ahmadi Z, et al. The surgical management of complicated pulmonary hydatid cysts. Med J Islam Repub Iran. 2004;18(1):1-5.

12. Alpay L, Lacin T, Ocakcioglu I, et al. Is Video-assisted thoracoscopic surgery adequate in treatment of pulmonary hydatidosis? Ann Thorac Surg. 2015;100(1):258-262. https://doi.org/10.1016/j.athoracsur.2015.03.011

13. Pawłowski Z, Eckert Z, Vuitton D, et al. Echinococcosis in humans: clinical aspects, diagnosis and treatment. In: 
WHO/OIE Manual on Echinococcosis in Humans and Animals, Eckert J, Gemmell MA, Meslin FX, Pawlowski Z (Eds), Office International des E 'pizooties, Paris 2001. p.43.

14. Halezeroglu S, Okur E, Tanyü MO. Surgical Management for Hydatid Disease. Thorac Surg Clin. 2012;22(3):37585. https://doi.org/10.1016/j.thorsurg.2012.04.004

15. Kosar A, Orki A, Haciibrahimoglu G, et al. Effect of capitonnage and cystotomy on outcome of childhood pulmonary hydatid cysts. J Thorac Cardiovasc Surg 2006;132:560-4.

16. Doğan R, Yüksel $M$, Cetin $G$, et al. Surgical treatment of hydatid cysts of the lung: report on 1055 patients. Thorax. 1989;44(3):192-199. https://doi.org/10.1136/thx.44.3.192

17. Bagheri R., Haghi SZ, Amini M, et al. Pulmonary hydatid cyst: Analysis of 1024 cases. Gen Thorac Cardiovasc Surg. 2011;59(2):105-109. https://doi.org/10.1007/s11748010-0690-z

18. Goni MO, Karim MF, Alam MK, et al. Capitonnage versus non-capitonnage surgery for pulmonary hydatid cyst: A head to head study. J Dhaka Med Coll. 2014;23(1):94101.

19. Sayir F, Cobanoğlu U, Sehitoğulları A, et al. Our eightyear surgical experience in patients with pulmonary cyst hydatid. Int J Clin Exp Med. 2012;5(1):64-71.

20. Turgut AT, Altinok T, Topçu $S$, et al. Local complications of hydatid disease involving thoracic cavity: Imaging findings. Eur J Radiol. 2009;70:49-56.

21. Lewall DB, McCorkell SJ. Rupture of echinococcal cysts: Diagnosis, classification, and clinical implications. AJR Am J Roentgenol. 1986;146:391-4.

22. Balci AE, Eren N, Eren Ş, et al. Ruptured hydatid cysts of the lung in children: Clinical review and results of surgery. Ann Thorac Surg. 2002;74:889-892.

\section{PEER REVIEW}

Not commissioned. Externally peer reviewed.

\section{CONFLICTS OF INTEREST}

The authors declare that they have no competing interests.

\section{FUNDING}

None

\section{ETHICS COMMITTEE APPROVAL}

Institutional Review Board Committee of Jordan University of Science and Technology approved this study, (Ref number: 75-2018).
Figure 1: CXR showing bilateral intact huge hydatid cysts

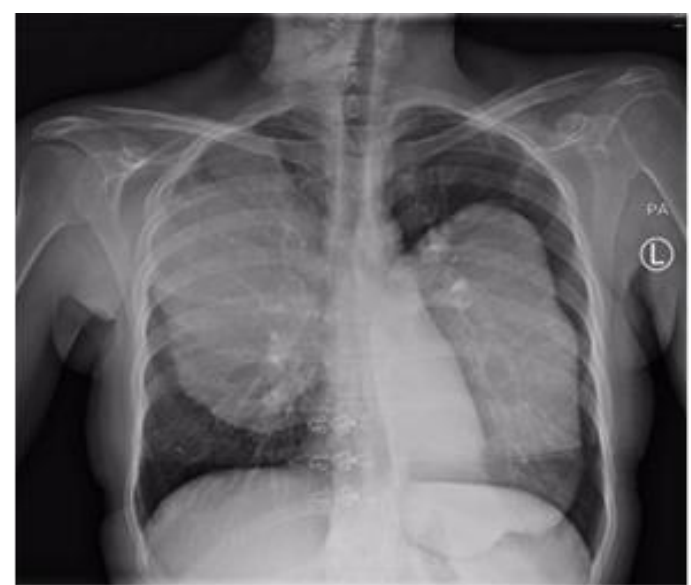

Figure 2A: CT scan of the chest showing bilateral intact hydatid cysts

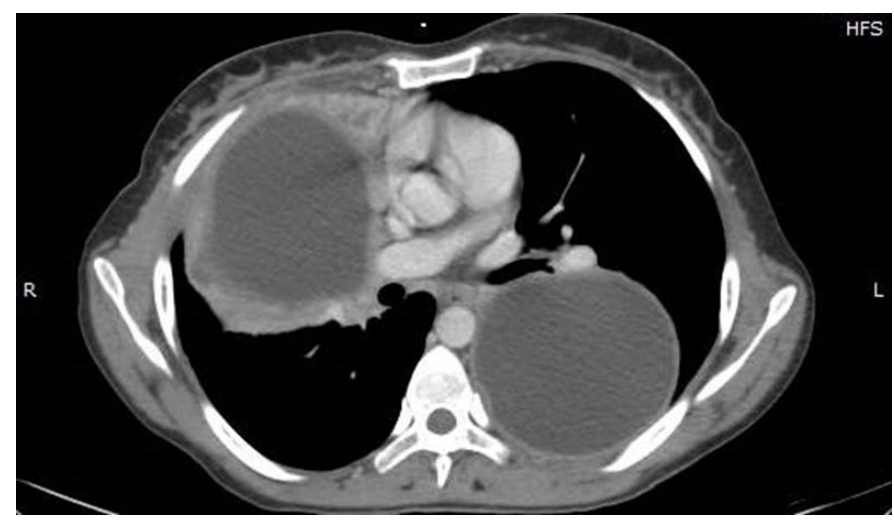

Figure 2B: Axial view of endobronchial and intrapleural rupture of a hydatid cyst

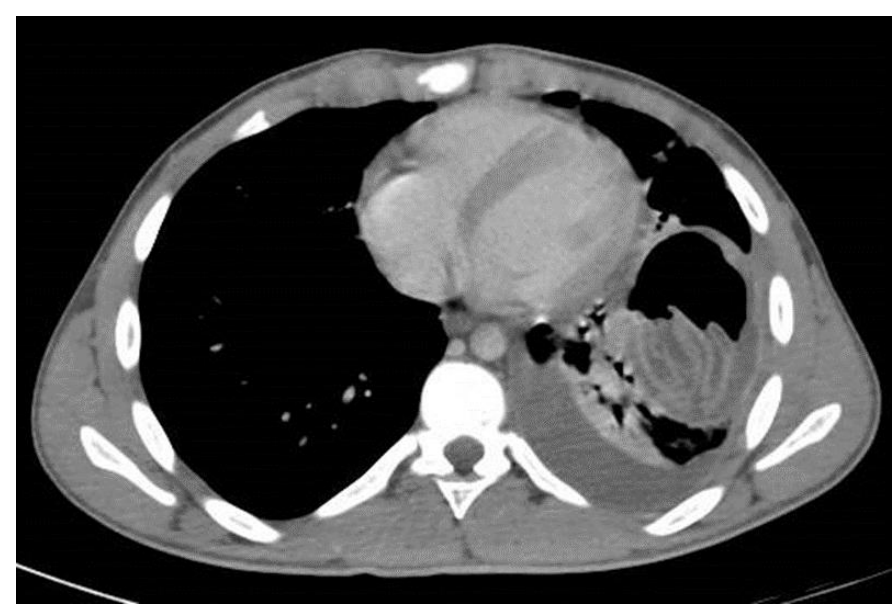


Figure 3: Removal of the intact cyst with gentle manipulation and assistance of positive pressure ventilation



Figure 4A: Illustrating the residual cavity after removal of the hydatid cyst

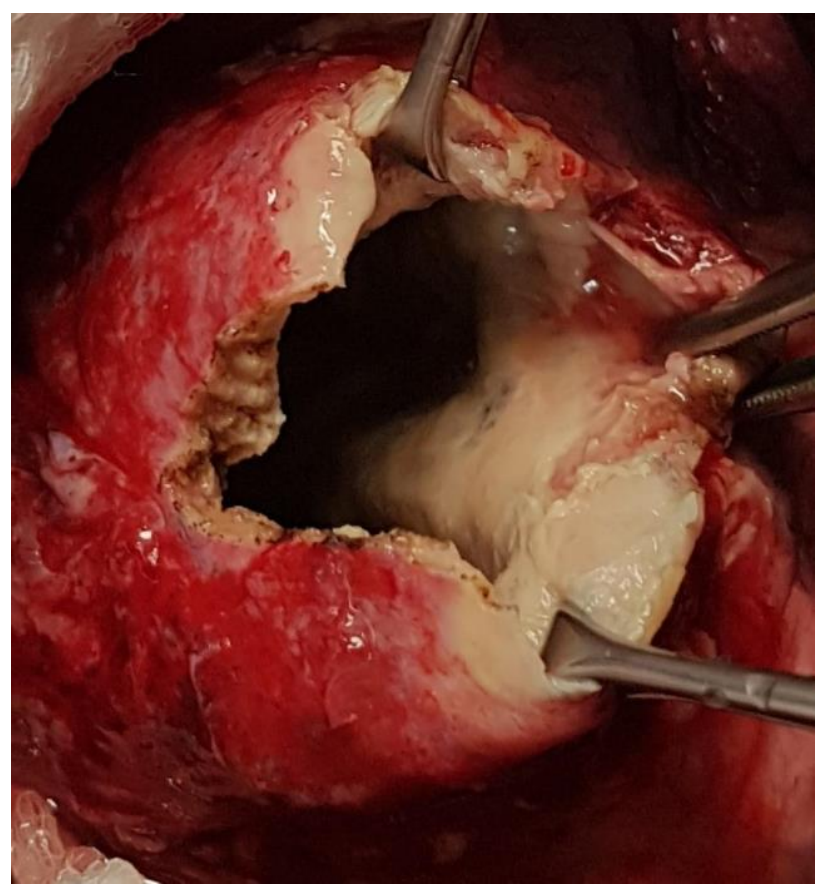

Figure 4B: Showing capitonnage of the residual cavity after removal of hydatid cyst

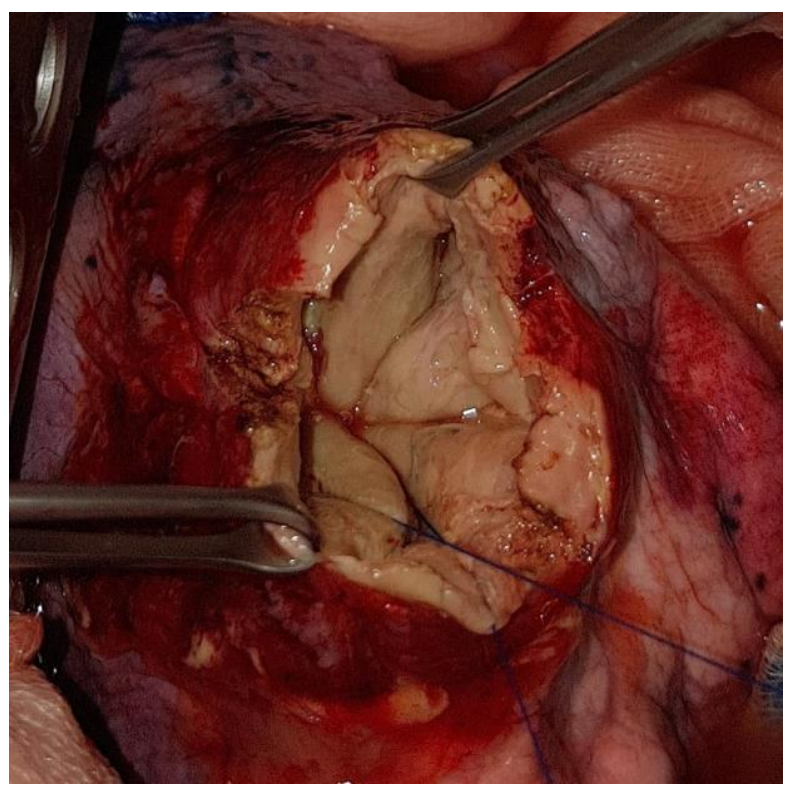

Table 1: Patients' Clinical and Demographic features

\begin{tabular}{|c|c|c|}
\hline & Number & $\%$ \\
\hline $\begin{array}{l}\text { Age (years): } \\
\text { Mean: } \\
\text { Range: }\end{array}$ & $\begin{array}{l}29.5 \pm 16.7 \\
8-75\end{array}$ & \\
\hline $\begin{array}{l}\text { Gender } \\
\text { Male: } \\
\text { Female: }\end{array}$ & $\begin{array}{l}42 \\
46\end{array}$ & $\begin{array}{l}48 \% \\
52 \%\end{array}$ \\
\hline $\begin{array}{l}\text { Presentation: } \\
\text { Asymptomatic } \\
\text { Cough } \\
\text { Shortness of breath } \\
\text { Chest pain } \\
\text { Cough with hemoptysis } \\
\text { Cough with watery sputum } \\
\quad \text { production and dyspnea } \\
\text { Cough and fever } \\
\text { Cough and chest pain } \\
\text { Discharging sinus } \\
\text { Right upper quadrant pain }\end{array}$ & $\begin{array}{l}21 \\
19 \\
17 \\
12 \\
7 \\
\\
5 \\
3 \\
2 \\
1 \\
1\end{array}$ & $\begin{array}{l}24 \% \\
22 \% \\
19 \% \\
14 \% \\
8 \% \\
\\
6 \% \\
3 \% \\
2 \% \\
1 \% \\
1 \%\end{array}$ \\
\hline $\begin{array}{l}\text { ELISA: } \\
\text { Positive } \\
\text { Negative } \\
\text { Unknown } \\
\text { Equivocal }\end{array}$ & $\begin{array}{l}39 \\
21 \\
27 \\
1\end{array}$ & $\begin{array}{l}44 \% \\
24 \% \\
31 \% \\
1 \%\end{array}$ \\
\hline $\begin{array}{l}\text { Peripheral Eosinophilia: } \\
\text { Positive } \\
\text { Negative } \\
\text { Unknown }\end{array}$ & $\begin{array}{l}51 \\
24 \\
13\end{array}$ & $\begin{array}{l}58 \% \\
27 \% \\
15 \%\end{array}$ \\
\hline
\end{tabular}


Table 2: Cyst characteristics

\begin{tabular}{|c|c|c|}
\hline & Number & $\%$ \\
\hline $\begin{array}{l}\text { Number: } \\
\text { Single } \\
\text { Single unilateral } \\
\text { Single bilateral } \\
\text { Multiple } \\
\text { Multiple unilateral } \\
\text { Multiple bilateral } \\
\text { Number of cysts } \\
\leq 3 \text { cysts } \\
>3 \text { cysts }\end{array}$ & $\begin{array}{l}63 \\
54 \\
9 \\
25 \\
19 \\
6 \\
\\
74 \\
14\end{array}$ & $\begin{array}{l}71.5 \% \\
61.3 \% \\
10.2 \% \\
28.5 \% \\
21.5 \% \\
7 \% \\
\\
84 \% \\
16 \%\end{array}$ \\
\hline $\begin{array}{l}\text { Organs involved: } \\
\text { Lung isolated } \\
\text { Liver } \\
\text { Spleen } \\
\text { Others }\end{array}$ & $\begin{array}{l}62 \\
23 \\
3 \\
\text { (Pouch of Douglas 2, } \\
\text { Breast 1, Thigh 1, } \\
\text { Chest Wall1, } \\
\text { Retroperitoneal 1) }\end{array}$ & $\begin{array}{l}70 \% \\
26 \% \\
3 \% \\
6 \%\end{array}$ \\
\hline $\begin{array}{l}\text { Lung cysts: } \\
\text { Unilateral } \\
\text { Right } \\
\text { Left } \\
\text { Bilateral }\end{array}$ & $\begin{array}{l}73 \\
32 \\
41 \\
15\end{array}$ & $\begin{array}{l}82.9 \% \\
36.3 \\
46.6 \\
17.1 \%\end{array}$ \\
\hline $\begin{array}{l}\text { Involved lobes: } \\
\text { Upper } \\
\text { Middle } \\
\text { Lower } \\
\end{array}$ & $\begin{array}{l}29 \\
6 \\
65 \\
\end{array}$ & $\begin{array}{l}33 \% \\
7 \% \\
73.8 \% \\
\end{array}$ \\
\hline $\begin{array}{l}\text { Cyst size (largest if } \\
\text { multiple): } \\
\text { Mean } \\
\text { Range }\end{array}$ & $\begin{array}{l}8.2 \pm 2.9 \mathrm{~cm} \\
5-18 \mathrm{~cm}\end{array}$ & \\
\hline $\begin{array}{l}\text { Cyst integrity (by CT } \\
\text { scan): } \\
\text { Intact } \\
\text { Ruptured } \\
\text { Contained } \\
\text { Communicating } \\
\text { Direct }\end{array}$ & $\begin{array}{l}56 \\
32 \\
7 \\
10 \\
15\end{array}$ & $\begin{array}{l}64 \% \\
37 \% \\
22 \% \\
31 \% \\
47 \%\end{array}$ \\
\hline
\end{tabular}

Table 3: Clinical Outcomes

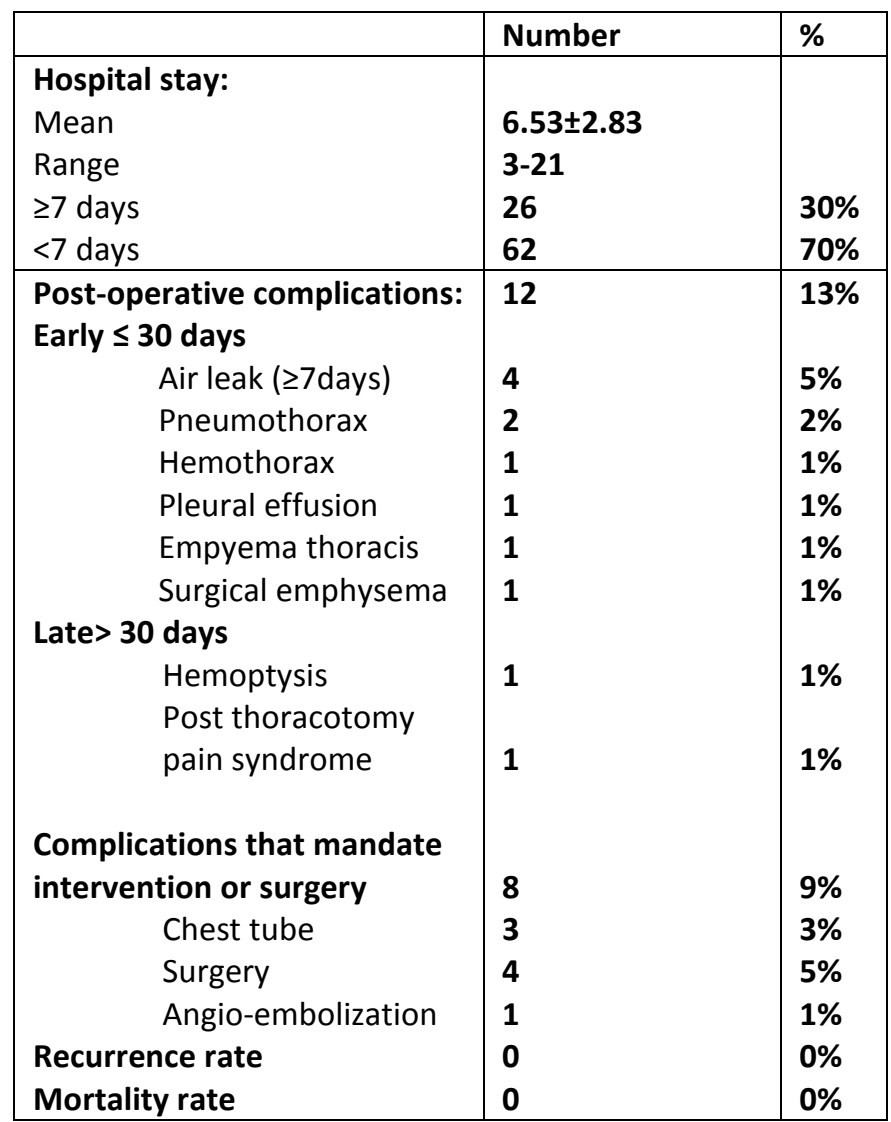

